\title{
Model Optimasi Fixturing Benda-Kerja dengan Prinsip 3-2-1
}

\author{
Mohammad Yazid Diratama ${ }^{1}$, Dadan Heryada Wigenaputra ${ }^{1}$, Isa Setiasyah Toha ${ }^{2 *}$
}

\begin{abstract}
To hold a workpiece firmly at its place, a fixture is required. Some previous studies have discussed the balance of forces and moments that are based on kinematic model, screw theory, contact force and position error. The most fundamental problem in the design of the fixture is to determine the coordinates of a locator and clamp and a clamping force, so that the workpiece is stable during the machining process. This paper discusses an optimization model to determine the coordinates of the locator and clamp and the clamping force, focusing to the balance of forces and moments. Specifically, the optimization model developed is used for solving the problem of fixturing the workpiece applying the 3-2-1 principle. Numerical examples are given to illustrate the application of the model. The optimization model is solved using standard nonlinear programming software.
\end{abstract}

Keywords: Fixture, force, moment, locator, clamp, optimization.

\section{Pendahuluan}

Penetap (fixture) merupakan alat bantu yang digunakan pada pemesinan, perakitan, inspeksi, dan berbagai operasi manufaktur lainnya. Dalam proses pemesinan, benda-kerja akan mengalami gaya dan momen pemotongan, sehingga diperlukan penetap untuk memegang benda-kerja agar diam pada tempatnya. Hal ini diperlukan agar bendakerja hasil pemesinan sesuai dengan spesifikasi desainnya. Penetap terdiri dari lokator dan klem. Lokator berperan untuk menjaga benda-kerja berada pada tempatnya, sedangkan klem berperan untuk menghilangkan pergerakan yang terjadi, dengan memberikan gaya yang akan melawan pergerakan benda-kerja.

Suatu benda-kerja pada ruang tiga dimensi, dapat bergerak pada dua-belas arah (memiliki dua-belas derajat kebebasan). Penetapan (fixturing) dengan prinsip 3-2-1 menempatkan tiga lokator bawah, dua lokator samping, dan satu lokator pada samping lainnya, sehingga benda-kerja hanya memiliki tiga derajat kebebasan. Untuk memegang benda kerja pada tempatnya (nol derajat kebabasan), digunakan satu klem atas, satu klem samping, dan satu klem samping lainnya, yang masing-masing berlawanan dengan arah lokator.

Untuk memegang benda-kerja pada tempatnya, diperlukan analisis keseimbangan gaya dan momen yang terjadi. Beberapa penelitian sebelumnya yang membahas ini diantaranya adalah Asada dan By [1] yang mengembangkan model kinematik penetap.

\footnotetext{
1 Politeknik Manufaktur Negeri Bandung. Jl. Kanayakan 21, Bandung 40135, Email: yazid@polman-bandung.ac.id; dadan_ heryada@polman-bandung.ac.id

${ }^{2}$ Fakultas Teknologi Industri, Jurusan Teknik Industri, Institut Teknologi Bandung, Jl. Ganesha 10, Bandung 40132. Email: isa_st@polman-bandung.ac.id

* Penulis korespondensi
}

Chou et al. [2] menerapkan teori ulir (screw theory) dalam merumuskan keseimbangan penetap untuk benda-kerja prismatik kaku, dalam upaya mendapatkan gaya klem yang fisibel. Ariastuti et al. [3] menggunakan model Chou untuk mendapatkan koordinat lokator dan klem, dengan cara memeriksa fisibilitas keseimbangan gaya dan momen dari koordinat lokator dan klem. Koordinat lokator dan klem ditentukan dengan pembagian simetris pada benda-kerja. Jika tidak fisibel, dilakukan penggeseran pada koordinat alternatif yang telah ditentukan. Nudu dan Toha [4] mengembangkan model/algoritma Ariastuti et al. [3] untuk penetapan pada penetap modular basis lubang. Titik-titik koordinat hasil pembagian simetri dibulatkan (integer) terhadap jarak antar lubang penetap modular basis lubang yang digunakan. Serupa dengan Nudu dan Toha [4], Diratama dan Toha [5] mengembangkan perangkat-lunak dan set penetap modular basis lubang untuk pembuatan komponen prismatik presstool.

Penelitian yang membahas permasalahan penetapan dengan memanfaatkan model optimasi antara lain Wang dan Pelinescu [6]. Penelitian tersebut melakukan analisis gaya kontak yang diformulasikan menjadi programa non-linear dengan fungsi tujuan minimum norm gaya pasif, dengan fungsi pembatas keseimbangan gaya dan momen yang linear. Qin dan Zhang [7] melakukan analisis kestabilan benda-kerja dengan mentransformasikan sistem persamaan keseimbangan gaya dan momen menjadi persoalan programa linear. Qin et al. [8] melakukan analisis dan optimasi skema penempatan penetap yang menghasilkan prinsip dan kriteria desain optimal. Qin et al. [9] melakukan analisis dan optimasi urutan pencekaman yang akan meminimumkan deformasi dan kesalahan posisi bendakerja dengan fungsi pembatas geometri dan deviasi. Krishnakumar dan Melkote [10] serta Kaya [11] melakukan optimasi tata-letak lokator untuk me- 
nentukan koordinat lokator dan klem agar pergeseran yang terjadi minimum. Dalam hal ini gaya klem diketahui/ditetapkan. Kedua penelitian tersebut tidak menggunakan programa matematika, tetapi menggunakan algoritma genetika (genetic algorithm). Serupa dengan kedua penelitian tersebut, Vishnupriyan, et al. [12] melakukan optimasi tata-letak lokator untuk memenuhi kebutuhan toleransi yang dipengaruhi oleh kesalahan penempatan, menggunakan algoritma genetika.

Penelitian-penelitian di atas merupakan penelitian yang penting dalam pembahasan desain penetap. Namun hal yang paling mendasar dalam desain penetap adalah menentukan koordinat lokator dan klem serta gaya klem, agar benda-kerja stabil selama proses pemesinan. Penelitian-penelitian tersebut di atas memfokuskan pada evaluasi fisibilitas koordinat dan besarnya gaya klem yang ditetapkan. Oleh karena itu, makalah ini akan membahas model optimasi penetapan benda-kerja untuk mendapatkan koordinat dan besarnya gaya klem, serta koordinat dan besarnya gaya reaksi lokator yang memperhatikan keseimbangan gaya dan momen. Solusi optimal yang diperoleh, dapat digunakan untuk mengevaluasi perubahan koordinat gaya pemesinan yang terjadi pada pembentukan benda-kerja

\section{Metode Penelitian}

\section{Model Penetapan Benda-kerja}

Elemen penetap (fixture elements) terbagi menjadi elemen aktif dan pasif. Lokator bawah dan lokator sisi adalah elemen penetap pasif, karena gaya yang bekerja berupa gaya reaksi. Klem adalah elemen penetap aktif, yang memberikan gaya untuk menahan gaya luar yang berupa gaya pemotongan/ pemesinan.

Model Chou merupakan persamaan kesetimbangan gaya pada elemen-elemen penetap (lokator dan klem). Ilustrasi gaya-gaya yang terjadi untuk penetapan, diperlihatkan pada Gambar 1.

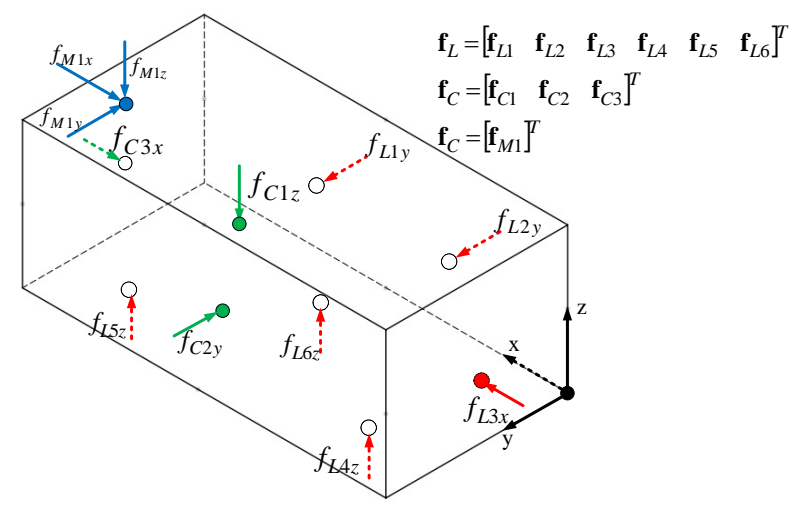

Gambar 1. Ilustrasi gaya-gaya pada penetapan
Dalam bentuk matriks, persamaan kesetimbangan gaya dan momen berbentuk:

$\boldsymbol{w}_{L} \cdot \boldsymbol{f}_{L}+\boldsymbol{w}_{C} \cdot \boldsymbol{f}_{C}+\boldsymbol{f}_{M} \cdot \boldsymbol{w}_{M}=\mathbf{0}$

dimana:

$\boldsymbol{w}_{L}$ matriks arah (arah gaya, serta arah dan panjang lengan momen) yang bekerja pada lokator.

$\boldsymbol{w}_{C}$ matriks arah klem.

$\boldsymbol{w}_{M}$ matriks arah pemotongan/pemesinan.

$\boldsymbol{f}_{L}$ matriks gaya yang bekerja pada lokator.

$\boldsymbol{f}_{C}$ matriks gaya klem.

$\boldsymbol{f}_{M}$ matriks gaya pemesinan.

Pada persamaan tersebut gaya berat diabaikan.

Permasalahan penetapan di sini adalah permasalahan untuk memastikan bahwa lokator menahan/ bersentuhan dengan benda-kerja. Menggunakan persamaan (1), gaya lokator dapat dinyatakan sebagai:

$\boldsymbol{f}_{L}=-\boldsymbol{w}_{L}^{-1}\left(\boldsymbol{f}_{C} \boldsymbol{w}_{C}+\boldsymbol{w}_{M} \boldsymbol{f}_{M}\right) \geq 0$

dimana format matriks arah dibentuk oleh arah normal searah sumbu $x, y, z$ dan arah momen putar pada sumbu $x, y, z$. Matriks gaya dibentuk oleh besarnya gaya pada arah sumbu $x, y, z$.

$\boldsymbol{w} .=\left[\begin{array}{c}\boldsymbol{n} \\ \boldsymbol{r} \times \boldsymbol{n}\end{array}\right]=\left[\begin{array}{ccc}n_{x} & 0 & 0 \\ 0 & n_{y} & 0 \\ 0 & 0 & n_{z} \\ 0 & -r_{z} \cdot n_{y} & r_{y} \cdot n_{z} \\ r_{z} \cdot n_{x} & 0 & -r_{x} \cdot n_{z} \\ -r_{y} \cdot n_{x} & r_{x} \cdot n_{y} & 0\end{array}\right], \boldsymbol{f} .=\left[\begin{array}{c}f_{x} \\ f_{y} \\ f_{z}\end{array}\right]$

dimana:

$\boldsymbol{w}$. matriks arah (arah gaya, serta arah \& panjang lengan momen)lokator $\left(\boldsymbol{w}_{L}\right)$, klem $\left(\boldsymbol{w}_{C}\right)$, atau pemesinan $\left(\boldsymbol{w}_{M}\right)$.

$\boldsymbol{n}$ matriks arah normal.

$\boldsymbol{r}$ matriks panjang lengan.

$\boldsymbol{f}$. matriks gaya lokator $\left(\boldsymbol{f}_{L}\right)$, klem $\left(\boldsymbol{f}_{C}\right)$, atau emesinan $\left(\boldsymbol{f}_{M}\right)$.

$f$. besarnya gaya pada arah sumbu $x, y, z$.

$r$ panjang lengan momen pada sumbu $x, y, z$.

$n$. normal searah sumbu $x, y, z$.

\section{Model Optimasi Penetapan Benda-kerja dengan Prinsip 3-2-1}

Dengan menggunakan prinsip 3-2-1, yaitu tiga lokator bawah, dua lokator samping, satu lokator samping lainnya, dan tiga klem, serta pemesinan dengan spindel tunggal, maka arah dan gaya-gaya yang bekerja pada benda-kerja dengan bidang datar yang saling ortogonal, diperlihatkan pada Gambar 2. Pada gambar tersebut, koordinat lokator dan klem belum mempertimbangkan keberadaan fitur (features) pemesinan. 


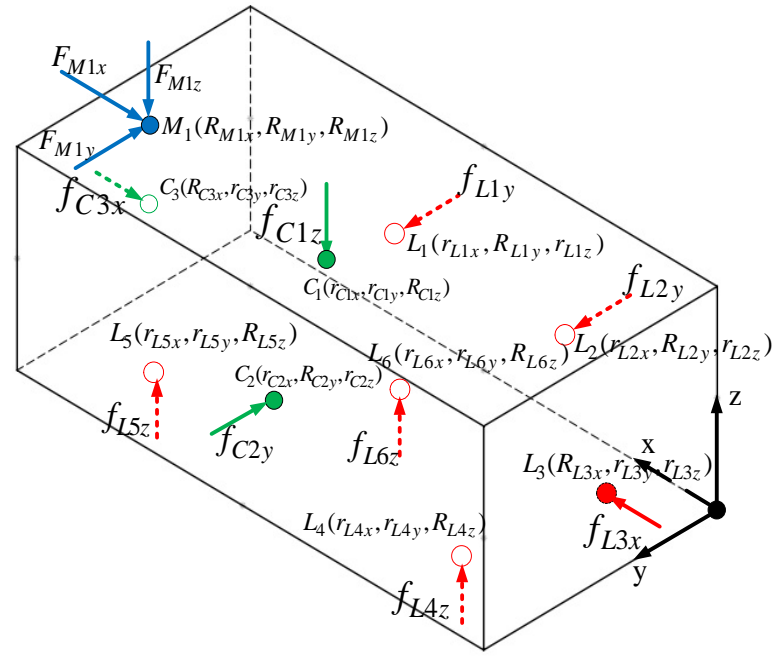

Gambar 2. Penetapan dengan prinsip 3-2-1

Notasi yang digunakan adalah:

$f_{i j k} \quad$ menyatakan besarnya jenis gaya $i$, pada titik yang ke $j$, dengan arah $k$. $i=L, C, M$; untuk $i=L, j=1,2, \ldots, 6$; untuk $i=C, j=1,2,3$; dan untuk $i=M, j=1 ; k=x, y, z$.

$L \quad$ indeks $i$ gaya lokator.

$C \quad$ indeks $i$ gaya klem.

$M \quad$ indeks $i$ gaya pemesinan.

$x \quad$ indeks $k$ dengan arah sumbu $x$.

$y \quad$ indeks $k$ dengan arah sumbu $y$.

$z \quad$ indeks $k$ dengan arah sumbu $z$.

$\left(r_{i j x}, r_{i j y}, r_{i j z}\right)$ titik koordinat gaya $i$, pada titik yang ke $j$, pada sumbu $x, y, z$.

$r_{i j k} \quad$ jarak gaya $i$ di titik yang ke $j$ pada sumbu $k$, dari pusat koordinat.

$R_{i j k} \quad$ jarak gaya $i$ di titik yang ke $j$ pada sumbu $k$, dari pusat koordinat yang sudah diketahui/ditentukan. $n$.. arah normal gaya, bernilai 1 jika arah positif, bernilai -1 jika arah negatif, bernilai nol jika tidak ada.

$m_{i j k} \quad$ menyatakan besarnya momen karena gaya $i$, pada titik yang ke $j$, dengan arah $k$.

$F_{i j k} \quad$ besarnya gaya $i$ di titik yang ke $j$ pada sumbu $k$ yang sudah diketahui.

Oleh karena pada model yang dikembangkan gaya pemesinan akan ditahan oleh gaya klem dan gaya lokator, maka secara teoritis benda-kerja diam, sehingga gaya gesek tidak terjadi atau dapat diabaikan.

Persamaan kesetimbangan gaya dan momen (1) terdiri dari perkalian matriks arah dan matriks gaya. Matriks arah $\boldsymbol{w}_{L}$ dan besar gaya $\boldsymbol{f}_{L}$ yang bekerja pada lokator adalah:

$$
\begin{aligned}
& \left.\boldsymbol{w}_{L}=\left[\begin{array}{lll}
\boldsymbol{w}_{L 1} & \ldots & \boldsymbol{w}_{L 6}
\end{array}\right]=\left[\begin{array}{c}
\boldsymbol{n}_{L 1} \\
\boldsymbol{r} \times \boldsymbol{n}_{L 1}
\end{array}\right] \quad \cdots\left[\begin{array}{c}
\boldsymbol{n}_{L 6} \\
\boldsymbol{r} \times \boldsymbol{n}_{L 6}
\end{array}\right]\right] \\
& \boldsymbol{w}_{L 1}=\left[\begin{array}{ccc}
n_{L 1 x} & 0 & 0 \\
0 & n_{L 1 y} & 0 \\
0 & 0 & n_{L 1 z} \\
0 & -r_{L 1 z} \cdot n_{L 1 y} & r_{L 1 y} \cdot n_{L 1 z} \\
r_{L 1 z} \cdot n_{L 1 x} & 0 & -r_{L 1 x} \cdot n_{L 1 z} \\
-r_{L 1 y} \cdot n_{L 1 x} & r_{L 1 x} \cdot n_{L 1 y} & 0
\end{array}\right] \\
& \boldsymbol{w}_{L 6}=\left[\begin{array}{ccc}
n_{L 6 x} & 0 & 0 \\
0 & n_{L 6 y} & 0 \\
0 & 0 & n_{L 6 z} \\
0 & -r_{L 6 z} \cdot n_{L 6 y} & r_{L 6 y} \cdot n_{L 6 z} \\
r_{L 6 z} \cdot n_{L 6 x} & 0 & -r_{L 6 x} \cdot n_{L 6 z} \\
-r_{L 6 y} \cdot n_{L 6 x} & r_{L 6 x} \cdot n_{L 6 y} & 0
\end{array}\right] \\
& \boldsymbol{f}_{L}=\left[\begin{array}{lll}
\boldsymbol{f}_{L 1} & \ldots & \boldsymbol{f}_{L 6}
\end{array}\right]^{T}=\left[\left[\begin{array}{l}
f_{L 1 x} \\
f_{L 1 y} \\
f_{L 1 z}
\end{array}\right] \quad \ldots\left[\begin{array}{l}
f_{L 6 x} \\
f_{L 6 y} \\
f_{L 6 z}
\end{array}\right]\right]^{T}
\end{aligned}
$$

Perkalian $\boldsymbol{w}_{L}$ dan $\boldsymbol{f}_{L}$ menghasilkan:

$\boldsymbol{w}_{L} \cdot \boldsymbol{f}_{L}=\left[\begin{array}{c}\sum_{j} f_{L j x} \\ \sum_{j} f_{L j y} \\ \sum_{j} f_{L j z} \\ \sum_{j} m_{L j x} \\ \sum_{j} m_{L j y} \\ \sum_{j} m_{L j z}\end{array}\right]=\left[\begin{array}{r}n_{L 1 x} \cdot f_{L 1 x}+\cdots+n_{L 6 x} \cdot f_{L 6 x} \\ n_{L 1 y} \cdot f_{L 1 y}+\cdots+n_{L 6 y} \cdot f_{L 6 y} \\ n_{L 1 z} \cdot f_{L 1 z}+\cdots+n_{L 6 z} \cdot f_{L 6 z} \\ -r_{L 1 z} \cdot n_{L 1 y} \cdot f_{L 1 y}+r_{L 1 y} \cdot n_{L 1 z} \cdot f_{L 1 z}-\cdots-r_{L 6 z} \cdot n_{L 6 y} \cdot f_{L 6 y}+r_{L 6 y} \cdot n_{L 6 z} \cdot f_{L 6 z} \\ r_{L 1 z} \cdot n_{L 1 x} \cdot f_{L 1 x}-r_{L 1 x} \cdot n_{L 1 z} \cdot f_{L 1 z}+\cdots+r_{L 6 z} \cdot n_{L 6 x} \cdot f_{L 6 x}-r_{L 6 x} \cdot n_{L 6 z} \cdot f_{L 6 z} \\ -r_{L 1 y} \cdot n_{L 1 x} \cdot f_{L 1 x}+r_{L 1 x} \cdot n_{L 1 y} \cdot f_{L 1 y}-\cdots-r_{L 6 y} \cdot n_{L 6 x} \cdot f_{L 6 x}+r_{L 6 x} \cdot n_{L 6 y} \cdot f_{L 6 y}\end{array}\right]$

$\boldsymbol{w}_{L} \cdot \boldsymbol{f}_{L}=\left[\begin{array}{c}f_{L 3 x} \\ f_{L 1 y}+f_{L 2 y} \\ f_{L 4 z}+f_{L 5 z}+f_{L 6 z} \\ -r_{L 1 z} \cdot f_{L 1 y}-r_{L 2 z} \cdot f_{L 2 y}+r_{L 4 y} \cdot f_{L 4 z}+r_{L 5 y} \cdot f_{L 5 z}+r_{L 6 y} \cdot f_{L 6 z} \\ r_{L 3 z} \cdot f_{L 3 x}-r_{L 4 x} \cdot f_{L 4 z}-r_{L 5 x} \cdot f_{L 5 z}-r_{L 6 x} \cdot f_{L 6 z} \\ r_{L 1 x} \cdot f_{L 1 y}+r_{L 2 x} \cdot f_{L 2 y}-r_{L 3 y} \cdot f_{L 3 x}\end{array}\right]$ 
Perkalian $\boldsymbol{w}_{C}$ dan $\boldsymbol{f}_{C}$ menghasilkan:

$$
\begin{aligned}
& \boldsymbol{w}_{C} \cdot \boldsymbol{f}_{C}=\left[\begin{array}{c}
\sum_{j} f_{C j x} \\
\sum_{j} f_{C j y} \\
\sum_{j} f_{C j z} \\
\sum_{j} m_{C j x} \\
\sum_{j} m_{C j y} \\
\sum_{j} m_{C j z}
\end{array}\right]=\left[\begin{array}{c}
n_{C 1 x} \cdot f_{C 1 x}+\cdots+n_{C 3 x} \cdot f_{C 3 x} \\
n_{C 1 y} \cdot f_{C 1 y}+\cdots+n_{L 6 y} \cdot f_{L 6 y} \\
n_{C 11 z} \cdot f_{C 1 z}+\cdots+n_{L 6 z} \cdot f_{L 6 z} \\
-r_{C 1 z} \cdot n_{C 1 y} \cdot f_{C 1 y}+r_{C 1 y} \cdot n_{C 1 z} \cdot f_{C 1 z}-\cdots-r_{C 3 z} \cdot n_{C 3 y} \cdot f_{C 3 y}+r_{C 3 y} \cdot n_{C 3 z} \cdot f_{C 3 z} \\
r_{C 1 z} \cdot n_{C 1 x} \cdot f_{C 1 x}-r_{C 1 x} \cdot n_{C 1 z} \cdot f_{C 1 z}+\cdots+r_{C 3 z} \cdot n_{C 3 x} \cdot f_{C 3 x}-r_{C 3 x} \cdot n_{C 3 z} \cdot f_{C 3 z} \\
-r_{C 1 y} \cdot n_{C 1 x} \cdot f_{C 1 x}+r_{C 1 x} \cdot n_{C 1 y} \cdot f_{C 1 y}-\cdots-r_{C 3 y} \cdot n_{C 3 x} \cdot f_{C 3 x}+r_{C 3 x} \cdot n_{C 3 y} \cdot f_{C 3 y}
\end{array}\right] \\
& \boldsymbol{w}_{C} \cdot \boldsymbol{f}_{C}=\left[\begin{array}{c}
-f_{C 11}-f_{C 2 x}-f_{C 3 x} \\
-f_{C 1 y}-f_{C 2 y}-f_{C 3 y} \\
-f_{C 1 z}-f_{C 2 z}-f_{C 3 z} \\
-r_{C 1 y} \cdot f_{C 1 z}+r_{C 2 z} \cdot f_{C 2 y} \\
r_{C 1 x} \cdot f_{C 1 z}-r_{C 3 z} \cdot f_{C 3 x} \\
-r_{C 2 x} \cdot f_{C 2 y}+r_{C 3 y} \cdot f_{C 3 x}
\end{array}\right] \text {. }
\end{aligned}
$$

Matriks arah dan besar gaya pemesinan $\left(\boldsymbol{w}_{M}\right.$ dan $\left.\boldsymbol{f}_{M}\right)$ adalah:

$$
\boldsymbol{w}_{M}=\left[\boldsymbol{w}_{M 1}\right]=\left[\begin{array}{c}
\boldsymbol{n}_{M 1} \\
\boldsymbol{r} \times \boldsymbol{n}_{M 1}
\end{array}\right]=\left[\begin{array}{ccc}
n_{M 1 x} & 0 & 0 \\
0 & n_{M 1 y} & 0 \\
0 & 0 & n_{M 1 z} \\
0 & -r_{M 1 z} \cdot n_{M 1 y} & r_{M 1 y} \cdot n_{M 1 z} \\
r_{M 1 z} \cdot n_{M 1 x} & 0 & -r_{M 1 x} \cdot n_{M 1 z} \\
-r_{M 1 y} \cdot n_{M 1 x} & r_{M 1 x} \cdot n_{M 1 y} & 0
\end{array}\right] .
$$

$\boldsymbol{f}_{M}=\left[\boldsymbol{f}_{M 1}\right]=\left[\begin{array}{lll}f_{M 1 x} & f_{M 1 y} & f_{M 1 z}\end{array}\right]^{T}$.

Perkalian $\boldsymbol{w}_{M}$ dan $\boldsymbol{f}_{M}$ menghasilkan:

$$
\boldsymbol{w}_{M} \cdot \boldsymbol{f}_{M}=\left[\begin{array}{c}
\sum_{j} f_{M j x} \\
\sum_{j} f_{M j y} \\
\sum_{j} f_{M j z} \\
\sum_{j} m_{M j x} \\
\sum_{j} m_{M j y} \\
\sum_{j} m_{M j z}
\end{array}\right]=\left[\begin{array}{c}
n_{M 1 x} \cdot f_{M 1 x} \\
n_{M 1 y} \cdot f_{M 1 y} \\
n_{M 1 z} \cdot f_{M 1 z} \\
-r_{M 1 z} \cdot n_{M 1 y} \cdot f_{M 1 y}+r_{M 1 y} \cdot n_{M 1 z} \cdot f_{M 1 z} \\
r_{M 1 z} \cdot n_{M 1 x} \cdot f_{M 1 x}-r_{M 1 x} \cdot n_{M 1 z} \cdot f_{M 1 z} \\
-r_{M 1 y} \cdot n_{M 1 x} \cdot f_{M 1 x}+r_{M 1 x} \cdot n_{M 1 y} \cdot f_{M 1 y}
\end{array}\right]=\left[\begin{array}{c}
-F_{M 1 x} \\
-F_{M 1 y} \\
-F_{M 1 z} \\
R_{M 1 z} \cdot F_{M 1 y}-R_{M 1 y} \cdot F_{M 1 z} \\
-R_{M 1 z} \cdot F_{M 1 x}+R_{M 1 x} \cdot F_{M 1 z} \\
R_{M 1 y} \cdot F_{M 1 x}-R_{M 1 x} \cdot F_{M 1 y}
\end{array}\right] .
$$

Substitusi persamaan (3), (4), dan (5) pada persamaan (1) menghasilkan:

$$
\boldsymbol{w}_{L} \cdot \boldsymbol{f}_{L}+\boldsymbol{w}_{C} \cdot \boldsymbol{f}_{C}+\boldsymbol{w}_{M} \cdot \boldsymbol{f}_{M}=\left[\begin{array}{c}
\sum_{j} f_{L j x} \\
\sum_{j} f_{L j y} \\
\sum_{j} f_{L j z} \\
\sum_{j} m_{L j x} \\
\sum_{j} m_{L j y} \\
\sum_{j} m_{L j z}
\end{array}\right]+\left[\begin{array}{c}
\sum_{j} f_{C j x} \\
\sum_{j} f_{C j y} \\
\sum_{j} f_{C j z} \\
\sum_{j} m_{C j x} \\
\sum_{j} m_{C j y} \\
\sum_{j} m_{C j z}
\end{array}\right]+\left[\begin{array}{c}
\sum_{j} f_{M j x} \\
\sum_{j} f_{M j y} \\
\sum_{j} f_{M j z} \\
\sum_{j} m_{M j x} \\
\sum_{j} m_{M j y} \\
\sum_{j} m_{M j z}
\end{array}\right]=\left[\begin{array}{c}
0 \\
0 \\
0 \\
0 \\
0 \\
0
\end{array}\right]
$$

Persamaan (6) menjadi:

$\sum_{i, j} f_{i j x}=\sum_{j} f_{L j x}+\sum_{j} f_{C j x}+\sum_{j} f_{M j x}=f_{L 3 x}-f_{C 3 x}-F_{M 1 x}=0$

$\sum_{i, j} f_{i j y}=\sum_{j} f_{L j y}+\sum_{j} f_{C j y}+\sum_{j} f_{M j y}=f_{L 1 y}+f_{L 2 y}-f_{C 2 y}-F_{M 1 y}=0$

$\sum_{i, j} f_{i j z}=\sum_{j} f_{L j z}+\sum_{j} f_{C j z}+\sum_{j} f_{M j z}=f_{L 4 z}+f_{L 5 z}+f_{L 6 z}-f_{C 1 z}-F_{M 1 z}=0$

$\sum_{i, j} m_{i j x}=\sum_{j} m_{L j x}+\sum_{j} m_{C j x}+\sum_{j} m_{M j x}=-r_{L 1 z} \cdot f_{L 1 y}-r_{L 2 z} \cdot f_{L 2 y}+r_{L 4 y} \cdot f_{L 4 z}+r_{L 5 y} \cdot f_{L 5 z}+r_{L 6 y} \cdot f_{L 6 z}-$ $r_{C 1 y} \cdot f_{C 1 z}+r_{C 2 z} \cdot f_{C 2 y}+R_{M 1 z} \cdot F_{M 1 y}-R_{M 1 y} \cdot F_{M 1 z}=0$

$\sum_{i, j} m_{i j y}=\sum_{j} m_{L j y}+\sum_{j} m_{C j y}+\sum_{j} m_{M j y}=r_{L 3 z} \cdot f_{L 3 x}-r_{L 4 x} \cdot f_{L 4 z}-r_{L 5 x} \cdot f_{L 5 z}-r_{L 6 x} \cdot f_{L 6 z}+r_{C 1 x} \cdot f_{C 1 z}-$

$$
r_{C 3 z} \cdot f_{C 3 x}-R_{M 1 z} \cdot F_{M 1 x}+R_{M 1 x} \cdot F_{M 1 z}=0
$$

$\sum_{i, j} m_{i j z}=\sum_{j} m_{L j z}+\sum_{j} m_{C j z}+\sum_{j} m_{M j z}=r_{L 1 x} \cdot f_{L 1 y}+r_{L 2 x} \cdot f_{L 2 y}-r_{L 3 y} \cdot f_{L 3 x}-r_{C 2 x} \cdot f_{C 2 y}+r_{C 3 y} \cdot f_{C 3 x}+$

$$
R_{M 1 y} \cdot F_{M 1 x}-R_{M 1 x} \cdot F_{M 1 y}=0
$$


Suatu penetapan akan memenuhi fungsinya jika lokator menahan atau bersentuhan dengan bendakerja, yaitu nilai $\boldsymbol{f}_{L} \geq \mathbf{0}$. Agar lokator bersentuhan dan tidak terjadi deformasipada benda-kerja, maka gaya lokator harusnon-negatif dan minimum. Dalam hal ini, gaya berat diabaikan, serta tidak terjadi gesekan dan defleksi/ deformasi pada lokator dan klem. Dengan demikian fungsi tujuan dari penetapan adalah meminimumkan $\boldsymbol{f}_{L}$, dengan memperhatikan kesembangan gaya dan momen yang terjadi. Formulasi dasar model optimasinya adalah:

Minimasi $Z=\sum_{j, k} \boldsymbol{f}_{L}$

dengan memperhatikan:

$\boldsymbol{w}_{L} \cdot \boldsymbol{f}_{L}+\boldsymbol{w}_{C} \cdot \boldsymbol{f}_{C}+\boldsymbol{w}_{M} \cdot \boldsymbol{f}_{M}=\mathbf{0}$

$\boldsymbol{f}_{L} \geq \mathbf{0}$, adalah pembatas non-negatif

Proposisi berikut menunjukkan bahwa meminimumkan gaya lokator, sama halnya dengan meminimumkan gaya klem. Dengan kata lain, meminimumkan gaya lokator, akan dengan sendirinya meminimumkan gaya klem.

\section{Proposisi:}

Untuk formulasi (13), fungsi tujuan yang meminimumkan gaya locator;

$Z=f_{L 3 x}+f_{L 1 y}+f_{L 2 y}+f_{L 4 z}+f_{L 5 z}+f_{L 6 z}$

ekivalen dengan meminimumkan gaya klem

$Z^{\prime}=f_{C 3 x}+f_{C 2 y}+f_{C 1 z}$

\section{Bukti:}

$$
\begin{aligned}
\operatorname{Min} Z & =\sum_{j, k} \boldsymbol{f}_{L}=\sum_{j} f_{L j x}+\sum_{j} f_{L j y}+\sum_{j} f_{L j z} . \\
& =f_{L 3 x}+f_{L 1 y}+f_{L 2 y}+f_{L 4 z}+f_{L 5 z}+f_{L 6 z}
\end{aligned}
$$

Substitusi persamaan (7), (8), dan (9) pada fungsi tujuan, diperoleh:

$$
\begin{aligned}
\text { Min } Z & =\left(f_{L 3 x}\right)+\left(f_{L 1 y}+f_{L 2 y}\right)+\left(f_{L 4 z}+f_{L 5 z}+f_{L 6 z}\right) \\
& =\left(f_{C 3 x}+F_{M 1 x}\right)+\left(f_{C 2 y}+F_{M 1 y}\right)+\left(f_{C 1 z}+F_{M 1 z}\right) \\
& =f_{C 3 x}+f_{C 2 y}+f_{C 1 z}+\left(F_{M 1 x}+F_{M 1 y}+F_{M 1 z}\right)
\end{aligned}
$$

Oleh karena $\left(F_{M 1 x}+F_{M 1 y}+F_{M 1 z}\right)$ adalah konstanta, maka:

$$
\begin{aligned}
\operatorname{Min} Z & =\left(f_{L 3 x}\right)+\left(f_{L 1 y}+f_{L 2 y}\right)+\left(f_{L 4 z}+f_{L 5 z}+f_{L 6 z}\right) \\
& \approx \operatorname{Min} Z^{\prime}=f_{C 3 x}+f_{C 2 y}+f_{C 1 z}
\end{aligned}
$$

Menggunakan fungsi tujuan (14), dan pembatas persamaan (7) sampai dengan (12), maka formulasi (13) menjadi:

$\operatorname{Min} Z=f_{L 3 x}+f_{L 1 y}+f_{L 2 y}+f_{L 4 z}+f_{L 5 z}+f_{L 6 z}$

dengan memperhatikan:

$$
\begin{aligned}
& f_{L 3 x}-f_{C 3 x}-F_{M 1 x}=0 \\
& f_{L 1 y}+f_{L 2 y}-f_{C 2 y}-F_{M 1 y}=0 \\
& f_{L 4 z}+f_{L 5 z}+f_{L 6 z}-f_{C 1 z}-F_{M 1 z}=0
\end{aligned}
$$

$$
\begin{aligned}
& -r_{L 1 z} \cdot f_{L 1 y}-r_{L 2 z} \cdot f_{L 2 y}+r_{L 4 y} \cdot f_{L 4 z}+r_{L 5 y} \cdot f_{L 5 z} \\
& +r_{L 6 y} \cdot f_{L 6 z}-r_{C 1 y} \cdot f_{C 1 z}+r_{C 2 z} \cdot f_{C 2 y}+R_{M 1 z} \cdot F_{M 1 y} \\
& -R_{M 1 y} \cdot F_{M 1 z}=0 \\
& r_{L 3 z} \cdot f_{L 3 x}-r_{L 4 x} \cdot f_{L 4 z}-r_{L 5 x} \cdot f_{L 5 z}-r_{L 6 x} \cdot f_{L 6 z} \\
& +r_{C 1 x} \cdot f_{C 1 z}-r_{C 3 z} \cdot f_{C 3 x}-R_{M 1 z} \cdot F_{M 1 x}+R_{M 1 x} \cdot F_{M 1 z}=0 \\
& r_{L 1 x} \cdot f_{L 1 y}+r_{L 2 x} \cdot f_{L 2 y}-r_{L 3 y} \cdot f_{L 3 x}-r_{C 2 x} \cdot f_{C 2 y} \\
& +r_{C 3 y} \cdot f_{C 3 x}+R_{M 1 y} \cdot F_{M 1 x}-R_{M 1 x} \cdot F_{M 1 y}=0
\end{aligned}
$$

Variabel keputusan formulasi penetapan tersebut adalah menentukan titik koordinat lokator $\left(r_{L 1 x}, r_{L 1 Z}\right)$, $\left(r_{L 2 x}, r_{L 2 z}\right), \quad\left(r_{L 3 y}, r_{L 3 z}\right), \quad\left(r_{L 4 x}, r_{L 4 y}\right), \quad\left(r_{L 5 x}, r_{L 5 y}\right)$, $\left(r_{L 6 x}, r_{L 6 y}\right)$, dan gaya yang bekerja pada lokator $f_{L 1 y}, f_{L 2 y}, f_{L 3 x}, f_{L 4 z}, f_{L 5 z}, f_{L 6 z}$; serta koordinat klem $\left(r_{C 1 x}, r_{C 1 y}\right),\left(r_{C 2 x}, r_{C 2 z}\right),\left(r_{C 3 y}, r_{C 3 z}\right)$, dan gaya klem $f_{C 1 z}, f_{C 2 y}, f_{C 3 x}$. Dalam hal ini, $R_{L 4 z}, R_{L 5 z}, R_{L 6 z}=0$; $R_{C 1 z}, R_{C 2 y}, R_{C 3 x}$, koordinat dan besarnya gaya pemotongan diketahui/ditentukan.

Untuk memenuhi prinsip 3-2-1, digunakan pembagian simetri, yaitu pembagian daerah penempatan lokator secara simetris, seperti yang diperlihatkan pada Gambar 3. Pembatas 3-2-1 yang sekaligus merupakan pembatas ukuran benda-kerja. Ukuran benda-kerja pada masing-masing sumbu adalah $\left(B_{x}, B_{y}, B_{z}\right)$, dan keberadaan lokator dari tepi bendakerja pada masing-masing sumbu tidak kurang dari $b_{x}, b_{y}, b_{z}$. Dengan demikian, formulasi umum model penetapan yang menggunakan prinsip 3-2-1 adalah:

$$
\begin{aligned}
& \text { Min } Z=f_{L 3 x}+f_{L 1 y}+f_{L 2 y}+f_{L 4 z}+f_{L 5 z}+f_{L 6 z} \\
& \text { dengan memperhatikan: } \\
& f_{L 3 x}-f_{C 3 x}-F_{M 1 x}=0 \\
& f_{L 1 y}+f_{L 2 y}-f_{C 2 y}-F_{M 1 y}=0 \\
& f_{L 4 z}+f_{L 5 z}+f_{L 6 z}-f_{C 1 z}-F_{M 1 z}=0 \\
& -r_{L 1 z} \cdot f_{L 1 y}-r_{L 2 z} \cdot f_{L 2 y}+r_{L 4 y} \cdot f_{L 4 z}+r_{L 5 y} \cdot f_{L 5 z}+ \\
& r_{L 6 y} \cdot f_{L 6 z}-r_{C 1 y} \cdot f_{C 1 z}+r_{C 2 z} \cdot f_{C 2 y}+R_{M 1 z} \cdot F_{M 1 y}- \\
& R_{M 1 y} \cdot F_{M 1 z}=0 \\
& r_{L 3 z} \cdot f_{L 3 x}-r_{L 4 x} \cdot f_{L 4 z}-r_{L 5 x} \cdot f_{L 5 z}-r_{L 6 x} \cdot f_{L 6 z}+ \\
& r_{C 1 x} \cdot f_{C 1 z}-r_{C 3 z} \cdot f_{C 3 x}-R_{M 1 z} \cdot f_{M 1 x}+ \\
& R_{M 1 x} \cdot F_{M 1 z}=0 \\
& r_{L 1 x} \cdot f_{L 1 y}+r_{L 2 x} \cdot f_{L 2 y}-r_{L 3 y} \cdot f_{L 3 x}-r_{C 2 x} \cdot f_{C 2 y}+ \\
& r_{C 3 y} \cdot f_{C 3 x}+R_{M 1 y} \cdot F_{M 1 x}-R_{M 1 x} \cdot F_{M 1 y}=0 \\
& \text { Pembatas non-negatif: } \\
& f_{L j k} \geq 0 \\
& \text { Pembatas } 3-2-1: \\
& r_{L 1 x} \geq 0.5 * B_{x}, r_{L 1 x} \leq B_{x}-b_{x} \\
& r_{L 2 x} \geq b_{x}, r_{L 2 x} \leq 0.5 * B_{x} \\
& r_{L 4 x} \geq b_{x}, r_{L 4 x} \leq 0.33 * B_{x} \\
& r_{L 5 x} \geq 0.67 * B_{x}, r_{L 5 x} \leq B_{x}-b_{x} \\
& r_{L 6 x} \geq 0.33 * B_{x}, r_{L 6 x} \leq 0.67 * B_{x} \\
& r_{L 3 y} \geq b_{y}, r_{L 3 y} \leq B_{y}-b_{y} \\
& r_{L 4 y} \geq 0.5 * B_{y}, r_{L 4 y} \leq B_{y}-b_{y} \\
& r_{L 5 y} \geq 0.5 * B_{y}, r_{L 5 y} \leq B_{y}-b_{y} \\
& r_{L 6 y} \geq b_{y}, r_{L 6 y} \leq 0.5 * B_{y} \\
& r_{L 1 z} \geq b_{z}, r_{L 1 z} \leq B_{z}-b_{z} \\
& r_{L 2 z} \geq b_{z}, r_{L 2 z} \leq B_{z}-b_{z} \\
&
\end{aligned}
$$


$r_{L 3 z} \geq b_{z}, r_{L 3 z} \leq B_{z}-b_{z}$

Pembatas klem:

Klem atas-z:

$r_{C 1 x} \geq b_{x}, r_{C 1 x} \leq B_{x}-b_{x}$

$r_{C 1 y} \geq b_{y}, r_{C 1 y} \leq B_{y}-b_{y}$

$r_{C 1 z}=B_{z}$

Klem sisi-y:

$r_{C 2 x} \geq b_{x}, r_{C 2 x} \leq B_{x}-b_{x}$

$r_{C 2 y}=B_{y}$

$r_{C 2 z} \geq b_{z}, r_{C 2 z} \leq B_{z}-b_{z}$

Klem sisi-x:

$r_{C 3 x}=B_{x}$

$r_{C 3 y} \geq b_{y}, r_{C 3 y} \leq B_{y}-b_{y}$

$r_{C 3 z} \geq b_{z}, r_{C 3 z} \leq B_{z}-b_{z}$

Selain menggunakan pembagian simetri, pembentukan persamaan pembatas 3-2-1 dan persamaan pembatas klem, perlu memperhatikan keberadaan fitur pemesinan.

Persamaan fungsi tujuan (17) merupakan persamaan linear. Persamaan pembatas keseimbangan gaya (18), (19), dan (20) merupakan persamaan linear.

Persamaan pembatas keseimbangan momen (21), (22), dan (23) merupakan persamaan non-linear. Persamaan pembatas 3-2-1 (25) dan pembatas klem (26) merupakan persamaan linear. Formulasi tersebut merupakan permasalahan pemrograman nonlinear. Untuk menyelesaikan formulasi persoalan tersebut, dapat digunakan perangkat-lunak pemrograman non-linear standar seperti OpenSolver, LINGO, atau lainnya.

Formulasi model optimasi penetapan yang dihasilkan merupakan model statis. Untuk mendapatkan koordinat lokator dan klem, serta besarnya gaya lokator dan klem, dilakukan dengan langkah berikut:

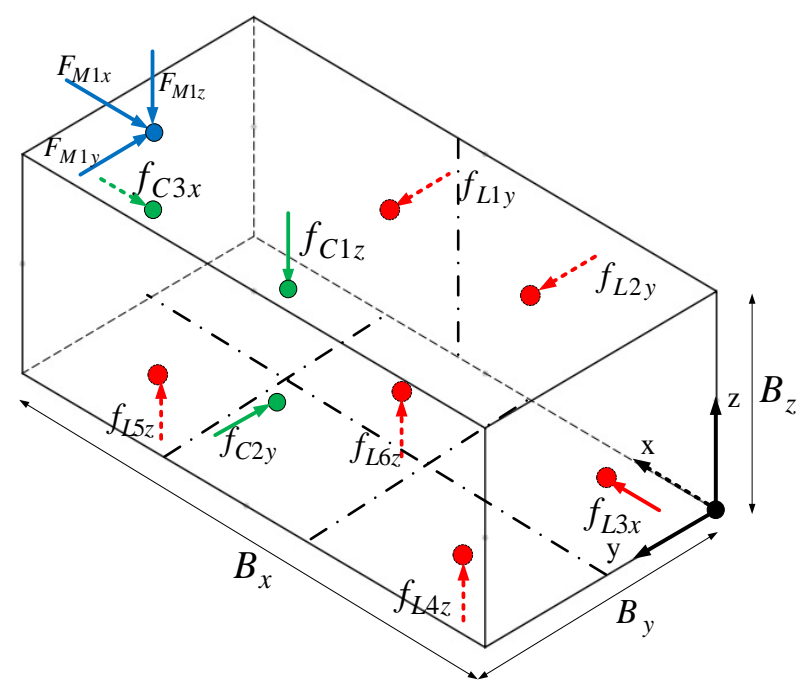

Gambar 3. Pembagian simetri lokator untuk prinsip 3-2-1
(1) Pilih koordinat dan gaya pemesinan pembentukan fitur manufaktur terbesar.

(2) Tetapkan arah gaya pemesinan berlawanan dengan arah gaya klem, gaya reaksi lokator adalah nol, maka gaya klem sama dengan gaya pemesinan, yaitu $f_{C j k}=f_{M 1 k}$.

(3) Susun formulasi model optimasi penetapan persamaan (17) sampai dengan (26), dan sertakan persamaan pembatas $f_{C j k}=f_{M 1 k}$.

(4) Dapatkan solusi formulasi model optimasi langkah (2) menggunakan perangkat-lunak pemrograman non-linear standar.

(5) Jika solusi optimal diperoleh, koordinat dan gaya lokator serta klem optimal diperoleh. Lokator bersentuhan denga benda-kerja.

(6) Jika tidak, perbaiki besarnya gaya pemesinan, kembali ke langkah (1).

Solusi optimal yang diperoleh adalah solusi optimal dengan koordinat gaya pemesinan terjauh. Harapannya adalah koordinat lokator dan klem serta besarnya gaya klem optimal tersebut dapat menahan gaya-gaya pemesinan untuk seluruh fitur manufaktur benda-kerja.

Untuk mengevaluasi perubahan koordinat gaya pemesinan, digunakan formulasi model dengan koordinat gaya pemesinan yang baru, koordinat lokator dan klem hasil optimasi, serta merelaksasi persamaan pembatas gaya klem optimal, yaitu $f_{C j k} \geq f_{M 1 k}$. Gaya klem terpilih adalah gaya klem terbesar hasil optimasi seluruh gaya pemesinan pembentukan fitur manufaktur benda-kerja.

\section{Hasil dan Pembahasan}

\section{Contoh Numerik}

Contoh numerik yang digunakan adalah contoh dari Krishnakumar dan Melkote [10] dan Kaya [11]. Permasalahan penetapan yang dibahas adalah mendapatkan koordinat lokator dan klem yang meminimumkan pergeseran. Pada contoh tersebut menggunakan bentuk dua-dimensi. Ukuran bendakerja adalah $B_{x}=304,8, B_{y}=254,0$, jarak lokator dan klem dari tepi benda-kerja adalah $b_{x}=5,0$, $b_{y}=5,0$. Koordinat dan besarnya gaya pemesinan adalah $M_{1}(203,2 ; 152,4)$ dan $F_{M 1 x}=F_{M 1 y}=889,6 N$. Besarnya gaya klem ditentukan, yaitu $F_{C 1 x}=$ $F_{C 2 x}=1779 N$. Variabel keputusannya adalah koordinat lokator $r_{L 1 x}, r_{L 2 x}, r_{L 3 y}$, dan koordinat klem $r_{C 1 x}, r_{C 2 y}$. Pembatas koordinat lokator adalah $5 \leq r_{L 1 x} \leq 148, \quad 156,8 \leq r_{L 2 x} \leq 299,8 ; \quad 5 \leq r_{L 3 y} \leq$ 249 , dan pembatas koordinat klem $5 \leq r_{C 1 x} \leq 300$, $5 \leq r_{C 2 y} \leq 249$

Menggunakan model optimasi yang dikembangkan, formulasi persoalan menjadi: 
$\operatorname{Min} Z=f_{L 3 x}+f_{L 1 y}+f_{L 2 y}$

dengan memperhatikan:

$f_{L 3 x}-f_{C 2 x}-F_{M 1 x}=0$

$f_{L 1 y}+f_{L 2 y}-f_{C 1 y}-F_{M 1 y}=0$

$r_{L 1 x} \cdot f_{L 1 y}+r_{L 2 x} \cdot f_{L 2 y}-r_{L 3 y} \cdot f_{L 3 x}+r_{C 2 y} \cdot f_{C 2 x}$

$r_{C 1 x} \cdot f_{C 1 y}+R_{M 1 y} \cdot F_{M 1 x}-R_{M 1 x} \cdot F_{M 1 y}=0$

Pembatas non-negatif:

$f_{L 3 x}, f_{L 1 y}, f_{L 2 y} \geq 0$

Pembatas 3-2-1:

$r_{L 1 x} \geq b_{x}, r_{L 1 x} \leq 0.5 * B_{x}$

$r_{L 2 x} \geq 0.5 * B_{x}, r_{L 2 x} \leq B_{x}-b_{x}$

$r_{L 3 y} \geq b_{y}, r_{L 3 y} \leq B_{y}-b_{y}$

Pembatas klem:

Klem sisi-y:

$r_{C 1 x} \geq b_{x}, r_{C 1 x} \leq B_{x}-b_{x}$

Klem sisi-x:

$r_{C 2 y} \geq b_{y}, r_{C 2 y} \leq B_{y}-b_{y}$

$f_{C 1 y}=F_{C 1 y}, f_{C 2 x}=F_{C 2 x}$.

Formulasi di atas diselesaikan menggunakan perangkat lunak pemrograman non-linear standar. Perbandingan solusi yang dihasilkan oleh Krishnakumar dan Melkote [10], Kaya [11], dan model yang dikembangkan diperlihatkan pada Tabel 1. Untuk mendapatkan koordinat lokator dan koordinat klem, Krishnakumar dan Melkote [10] dan Kaya [11] menggunakan algoritma genetika.

Nilai fungsi tujuan dari ke tiga model di atas tidak berbeda. Hal ini disebabkan karena besarnya gaya klem yang digunakan telah ditentukan dengn nilai yang sama.

Untuk mendapatkan koordinat lokator dan koordinat klem, serta besarnya gaya lokator dan klem yang optimal, formulasi model optimasi diselesaikan dengan mengikuti langkah-langkah yang telah diusulkan, yaitu:

Koordinat dan gaya pemesinan adalah $M_{1}(203,2 ; 152,4)$ dan $F_{M 1 x}=F_{M 1 y}=889,6$.

Arah gaya klem negatif, arah gaya pemesinan positif. Gaya reaksi lokator adalah nol. Gaya klem $f_{C 1 y}=889,6, f_{C 2 x}=889,6$.

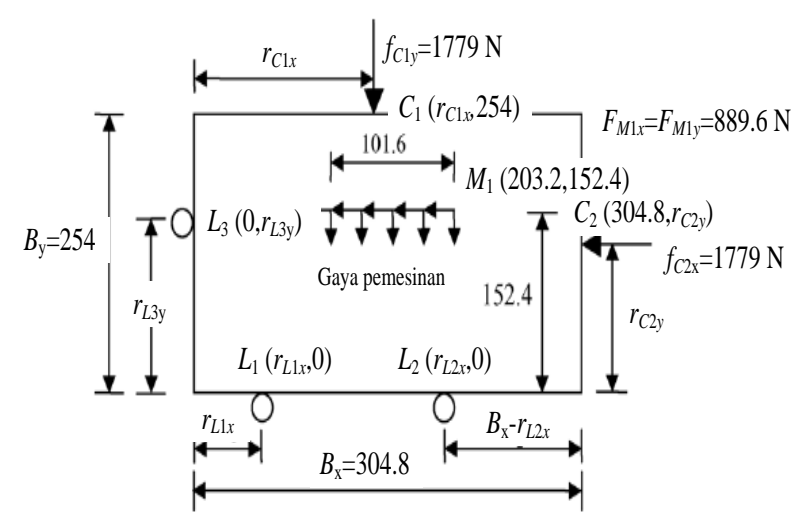

Gambar 4. Tata letak penetap dua-dimensi (Kaya [11]).
Formulasi persoalan adalah persamaan (27) sampai dengan (33), dan persamaan pembatas $f_{C 1 y}=889,6$, $f_{C 2 x}=889,6$.

Solusi optimal:

Nilai fungsi tujuan $=3558,40$, koordinat lokator $r_{L 1 x}^{*}=5,0, \quad r_{L 2 x}^{*}=156,80, \quad r_{L 3 y}^{*}=83,32$, besarnya gaya lokator $f_{L 1 y}^{*}=334,08, \quad f_{L 2 y}^{*}=1445,12$, $f_{L 3 x}^{*}=1779,20, \quad$ koordinat klem $r_{C 1 x}^{*}=44,16$, $r_{C 2 y}^{*}=5,0$, besarnya gaya klem $f_{C 1 y}^{*}=889,60$, $f_{C 2 y}^{*}=889,60$.

Solusi optimal diperoleh. Selama proses pemesinan, lokator bersentuhan denga benda-kerja.

Solusi optimal penetapan adalah:

Nilai fungsi tujuan $=3558,40$.

Koordinat lokator $r_{L 1 x}^{*}=5,0, r_{L 2 x}^{*}=156,80, r_{L 3 y}^{*}=$ 83,32.

Besarnya gaya lokator lokator $f_{L 1 y}^{*}=334,08$, $f_{L 2 y}^{*}=1445,12, f_{L 3 x}^{*}=1779,20$. Koordinat klem $r_{C 1 x}^{*}=44,16, r_{C 2 y}^{*}=5,0$. Besarnya gaya klem $f_{C 1 y}^{*}=889,60, f_{C 2 y}^{*}=889,60$, lebih kecil dari gaya klem yang ditentukan.

Dengan menggunakan koordinat lokator dan klem, serta besarnya gaya klem optimal yang direlaksasi, $f_{C 1 y} \geq 889,60, f_{C 2 y} \geq 889,60$, dilakukan evaluasi terhadap perubahan koordinat pemesinan. Pada contoh ini digunakan tiga buah titik koordinat pada lintasan pemesinan, yaitu titik koordinat pemesinan awal, tengah, dan akhir. Solusi optimal yang diperoleh diperlihatkan pada Tabel 2 .

Terlihat bahwa solusi optimal penetapan awal dapat menahan gaya pemesinan di titik-titik lintasan pemesinannya, yang ditunjukkan oleh besarnya gaya reaksi lokator yang non-negatif.

Contoh numerik untuk benda-kerja tiga-dimensi adalah komponen presstool seperti pada Gambar 5. Pada gambar tersebut diperlihatkan fitur manufakturnya. Ukuran benda-kerja adalah $B_{x}=140$, $B_{y}=80, B_{z}=20$, jarak lokator dan klem dari tepi benda-kerja adalah $b_{x}=5, b_{y}=5, b_{z}=5$. Koordinat dan besarnya gaya pemesinan adalah $M_{1}(120,60,20)$ dan $F_{M 1 x}=F_{M 1 y}=F_{M 1 z}=3782 \mathrm{~N}$.

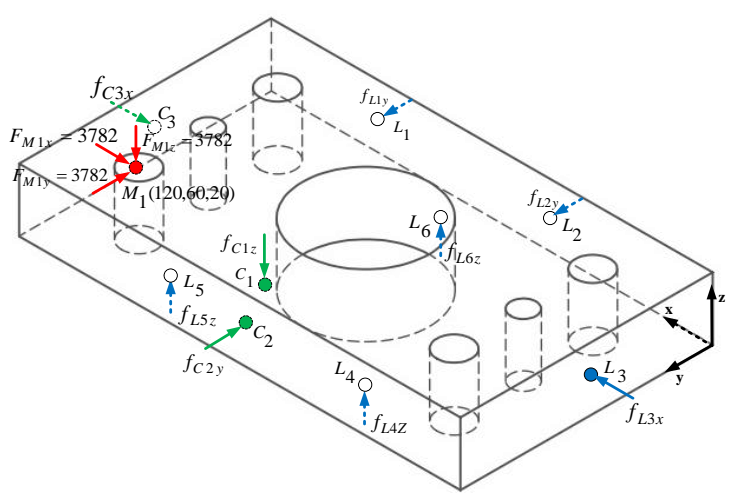

Gambar 5. Komponen presstool. 
Tabel 1. Perbandingan solusi Krishnakumar \& Melkote, Kaya, dan model yang dikembangkan.

\begin{tabular}{|c|c|c|c|c|c|c|c|c|c|c|}
\hline & \multicolumn{3}{|c|}{ Koordinat lokator } & \multicolumn{2}{|c|}{ Koordinat klem } & \multicolumn{3}{|c|}{ Gaya reaksi locator } & \multirow{2}{*}{$\begin{array}{l}\text { Nilai fungsi } \\
\text { tujuan }\end{array}$} & \multirow{2}{*}{ Keterangan } \\
\hline & $r_{L 1 x}$ & $r_{L 2 x}$ & $r_{L 3 x}$ & $r_{C 1 x}$ & $r_{C 1 x}$ & $f_{L 1 y}$ & $f_{L 2 y}$ & $f_{L 3 y}$ & & \\
\hline $\begin{array}{l}\text { Krihnakumur \& } \\
\text { Melkote[10] }\end{array}$ & 50,4 & 203,2 & 101,6 & 152,4 & 50,8 & 295,76 & 2372,84 & 2668,6 & 5337,2 & $\begin{array}{l}\text { Gaya reaksi lokator } \\
\text { dan nilai fungsi }\end{array}$ \\
\hline $\begin{array}{l}\text { Kaya[11] } \\
\text { (Run 3) }\end{array}$ & 126,7 & 230,5 & 97,5 & 235,2 & 69,8 & 149,19 & 2519,41 & 2668,6 & 5337,2 & $\begin{array}{l}\text { tujuan: Hasil } \\
\text { pengolahan }\end{array}$ \\
\hline $\begin{array}{l}\text { Model yang } \\
\text { dikembangkan }\end{array}$ & 5,0 & 156,8 & 63,97 & 5,0 & 5,0 & 1334,3 & 1334,3 & 2668,6 & 5337,2 & Hasil optimasi \\
\hline
\end{tabular}

Tabel 2. Gaya klem dan reaksi lokator optimal pada tiga titik koordinat pemesinan

\begin{tabular}{|c|c|c|c|c|c|c|c|}
\hline \multicolumn{2}{|c|}{ Koordinat pemesinan } & \multicolumn{2}{|c|}{ Gaya klem optimal } & \multicolumn{3}{|c|}{ Gaya reaksi lokator optimal } & \multirow{2}{*}{ Nilai fungsi tujuan } \\
\hline$r_{M 1 x}$ & $r_{M 1 y}$ & $f_{C 1 y}^{*}$ & $f_{C 2 x}^{*}$ & $f_{L 1 y}^{*}$ & $f_{L 2 y}^{*}$ & $f_{L 3 x}^{*}$ & \\
\hline 203,2 & 152,4 & 889,06 & 889,06 & 334,08 & 1445,12 & 1779,20 & 3558,4 \\
\hline 152,4 & 152,4 & 889,06 & 889,06 & 631,79 & 1147,42 & 1779,20 & 3558,4 \\
\hline 101,6 & 152,4 & 889,06 & 889,06 & 929,49 & 849,71 & 1779,20 & 3558,4 \\
\hline
\end{tabular}

Tabel 3. Gaya klem optimal pada titik koordinat fitur pemesinan

\begin{tabular}{rcccccc}
\hline \multicolumn{3}{c}{ Koordinat pemesinan } & \multicolumn{3}{c}{ Gaya klem optimal } & \multirow{2}{*}{ Nilai fungsi tujuan } \\
\cline { 2 - 5 }$r_{M 1 x}$ & $r_{M 1 y}$ & $r_{M 1 z}$ & $f_{C 1 z}^{*}$ & $f_{C 2 y}^{*}$ & $f_{C 3 x}^{*}$ & 22692,0 \\
120 & 60 & 20 & 3782,0 & 3782,0 & 3782,0 & 23226,9 \\
120 & 40 & 20 & 4316,9 & 3782,0 & 3782,0 & 23762,3 \\
120 & 20 & 20 & 4852,3 & 3782,0 & 3782,0 & 25217,4 \\
20 & 20 & 20 & 6307,4 & 3782,0 & 3782,0 & 22692,0 \\
70 & 40 & 20 & 3782,0 & 3782,0 & 3782,0 & 33510,8 \\
20 & 40 & 20 & 3782,0 & 3782,0 & 14600,8 & 53789,6 \\
20 & 60 & 20 & 3782,0 & 3782,0 & 34879,6 & \\
\hline
\end{tabular}

Formulasi penetapan menggunakan persamaan (17) sampai dengan persamaan (26), yang melibatkan 21 variabel dan 6 persamaan utama, ditambah 27 persamaan pembatas 3-2-1 dan 10 persamaan pembatas klem. Formulasi model optimasi diselesaikan dengan mengikuti langkah-langkah yang telah diusulkan. Solusi optimal penetapan adalah:

Nilai fungsi tujuan $=22692,0$.

Koordinat lokator $r_{L 1 x}^{*}=70,0, r_{L 1 z}^{*}=5,0, r_{L 2 x}^{*}=5,0$, $r_{L 2 z}^{*}=5,0, \quad r_{L 3 y}^{*}=8,73, r_{L 3 z}^{*}=15,0, \quad r_{L 4 x}^{*}=30,0$, $r_{L 4 y}^{*}=70,0, r_{L 5 x}^{*}=93,8, r_{L 5 y}^{*}=70,0, r_{L 6 x}^{*}=76,36$, $r_{L 6 y}^{*}=5,0$.

Besarnya gaya lokator $f_{L 1 y}^{*}=4033,94, f_{L 2 y}^{*}=$ $3530,06, \quad f_{L 3 x}^{*}=7564,0, \quad f_{L 4 z}^{*}=0,2280, \quad f_{L 5 z}^{*}=$ $6400,08, f_{L 6 z}^{*}=1163,69$.

Koordinat klem $r_{C 1 x}^{*}=57,23, r_{C 1 y}^{*}=75,0, r_{C 2 x}^{*}=$ $6,87, r_{C 2 z}^{*}=5,0, r_{C 3 y}^{*}=5,0, r_{C 3 z}^{*}=5,0$.

Besarnya gaya klem $f_{C 1 z}^{*}=3782,0, f_{C 2 y}^{*}=3782,0$, $f_{C 3 x}^{*}=3782,0$.

Hasil evluasi terhadap koordinat fitur manufaktur benda-kerja diperlihatkan pada Tabel 3. Gaya reaksi lokator optimal pada seluruh koordinat pemesinan non-negatif.

Berdasarkan pada tabel di atas, maka koordinat lokator dan klem solusi optimal sebelumnya digunakan untuk menahan gaya pemesinan di semua koordinat pemesinannya. Gaya klem yang diperlukan adalah $3782,0 \leq f_{C 1 z}^{*} \leq 6307,4, \quad f_{C 2 y}^{*}=3782,0$, $3782,0 \leq f_{C 3 x}^{*} \leq 34879,6$.

\section{Analisis dan Pembahasan}

Koordinat lokator dan klem yang dihasilkan oleh Krishnakumar dan Melkote [10], Kaya[11], dan model yang dikembangkan berbeda, namun nilai fungsi tujuan gaya lokatornya adalah sama. Hal ini menunjukkan bahwa terdapat alternatif solusi optimal; sesuai dengan apa yang dikemukakan oleh Kaya [11]. Solusi optimal gaya klem yang dihasilkan oleh model yang dikembangkan, lebih kecil dari gaya klem yang ditentukan oleh Krishnakumar dan Melkote [10], dan Kaya [11].

Model optimasi yang dikembangkan selain dapat menghasilkan solusi optimal penetapan, juga dapat digunakan untuk mengevaluasi perubahan posisi pemesinan. Gaya klem optimal hasil evaluasi, nilai yang terbesarnya merupakan gaya klem terbesar untuk pembentukan semua fitur manufaktur benda-kerja.

Penyelesaian formulasi permasalahan dilakukan dengan menggunakan perangkat-lunak pemrograman non-linear standar. Pada perangkat-lunak ini dipilih metode Global Solver. Metode ini menggunakan algoritma gradien menurun (generalized reduced gradient), yang dilengkapi dengan algoritma pemecahan non-konveks menjadi sub-sub persoalan konveks linear. Penentuan solusi optimalan global dari sub-sub persoalan, dilakukan dengan teknik pencabangan dan pemilihan (branch and bound). 


\section{Simpulan}

Model optimasi penetapan benda-kerja dengan prinsip 3-2-1 yang dikembangkan, menghasilkan formulasi untuk penetapan dengan fungsi tujuan berupa persamaan linear, dan fungsi pembatas berupa persamaan linear dan non-linear. Fungsi tujuan meminimumkan besarnya gaya reaksi lokator, yang dengan sendirinya akan meminimumkan besarnya gaya klem. Formulasi model merupakan model statis. Formulasi persoalan melibatkan 21 variabel dan 43 persamaan pembatas.

Menggunakan formulasi ini dapat diperoleh koordinat lokator dan klem, serta gaya lokator dan klem yang minimum. Besarnya gaya klem minimum lebih besar atau sama dengan besarnya gaya pemesinan. Solusi optimal model, dapat digunakan untuk mengevaluasi dinamika pemesinan dalam pembentukan seluruh fitur manufaktur benda-kerja.

Formulasi model dapat diselesaikan menggunakan perangkat-lunak pemrograman non-linear standar. Metode penyelesaian persoalan non-linear pada perangkat-lunak standar yang digunakan adalah Global Solver

\section{Daftar Pustaka}

1. Asada, H. and By, A.B., Kinematics Analysis of Workpart Fixturing for Flexible Assembly with Automatically Reconfigurable Fixtures, IEEE Journal of Robotics and Automation, RA-1(2), 1985, pp. 86-93.

2. Chou, Y-C., Chandru, V., and Barash, M.M., A Mathematical Approach to Automated Configuration of Machining Fixtures: Analysis and Synthesis, ASME Journal of Engineering for Industry, 111, 1989, pp. 299-306.

3. Ariastuti, R., Anastesia, dan Toha, I.S., Algoritma Penentuan Titik Pencekaman Benda Kerja Untuk Proses Pemesinan Komponen Prismatik, Jurnal Teknik dan Manajemen Industri, 18(2), 1998, pp.36-47.
4. Nudu, J.H., dan Toha, I.S., Algoritma Penentuan Titik Pencekaman Hole-Based Modular Fixture, Jurnal Teknik Industri, 10(2), 2008, pp. 112-123.

5. Diratama, M.Y., dan Toha, I.S., Perancangan Penetap (Fixture) Komponen Prismatik Presstool dengan Menggunakan Pendekatan Analitik pada Penetap Modular Berbasis Lubang (Hole Based Modular Fixture), Prosiding Seminar Nasional Rekayasa dan Teknologi Manufaktur STEMAN 2016, Bandung, 2016, pp. I-1-I-6.

6. Wang, M.Y. and Pelinescu, D.M., Contact Force Prediction and Force Closure Analysis of a Fixtured Rigid Workpiece with Friction, Journal of Manufacturing Science and Engineering, 125, 2003, pp. 325-332.

7. Qin, G.H. and Zhang, W.H., Modeling and Analysis of Workpiece Stability Based on the Linear Programming Method, International Journal of Advanced Manufacturing Technology, 32(1), 2007, pp. 78-91.

8. Qin, G.H., Zhang, W.H., and Wan, M., A Mathematical Approach to Analysis and Optimal Design of a Fixture Locating Scheme, International Journal of Advanced Manufacturing Technology, 29(3), 2006, pp. 349-359.

9. Qin, G.H., Zhang, W.H., and Wan, M., Analysis and Optimal Design of Fixture Clamping Sequence, Journal of Manufacturing Science and Engineering, 128, 2006, pp. 482-493.

10. Krishnakumar, K. and Melkote, S.N., Machining Fixture Layout Optimization using the Genetic Algorithm, International Journal of Machine Tools \& Manufacture, 40, 2000, pp 579598.

11. Kaya, N., Machining Fixture Locating and Clamping Position Optimization using Genetic Algorithm, Computer in Industry, 57, 2006, pp. 112-120.

12. Vishnupriyan, S., Majumder, M.C., and Ramachandran, K.P., Optimization of Machining Fixture Layout for Tolerance Requirements under the Influence of Locating Errors, International Journal of Engineering, Science and Technology, 2(1), 2010, pp. 152-162. 